\title{
CUENTOS DE MI TÍA PANCHITA COMO UNA MANIFESTACIÓN DEL GÉNERO DENOMINADO LITERATURA INFANTIL
}

\author{
Gilda Pacheco Acuña
}

\begin{abstract}
RESUMEN
Este artículo discute la naturaleza del género de la literatura infantil enfatizando tres aspectos: la presencia de elementos folclóricos, el conflicto entre la realidad y la fantasía, y la finalidad de los textos infantiles. Cuentos de mi Tía Panchita sirve como texto literario ilustrativo que facilita la exploración de tales temas.

Palabras clave: Literatura infantil, Cuentos de mi tía Panchita, Carmen Lyra.
\end{abstract}

\section{ABSTRACT}

\begin{abstract}
This article discusses the nature of the literary genre known as Children's literature and emphasizes three aspects: the presence of folkloric elements, the conflict between reality and fantasy and the objective or aim of children's texts. Cuentos de mi Tía Panchita serves as an illustrative literary text that facilitates the exploration of such themes.

Key words: Children's literature, Cuentos de mi tía Panchita, Carmen Lyra.
\end{abstract}

Carmen Lyra fue una ávida lectora que, debido a su formación como educadora y a su obra Cuentos de mi Tía Panchita, siempre ha estado y estará ligada al campo de la literatura infantil. Lyra obtuvo su certificado de Maestra Normal en la Sección de Pedagogía del Colegio Señoritas en 1905 (CTP 1994: I) y fue maestra en varias escuelas de San José y de Heredia. En 1920, viajó a Francia para estudiar sistemas de educación primaria. Además, fue la precursora, en el ámbito nacional, de muchos aspectos relacionados con el género de la literatura infantil, pues Carmen Lyra no sólo fue la primera persona que enseñó literatura infantil en nuestro país, sino también la creadora de "la cátedra de Literatura Infantil en la Escuela Normal de Costa Rica” (Dobles Rodríguez 1999: 4). Además, Carmen Lyra fue “(...) la primera en Costa Rica que fundó un centro de educación preescolar"1 (Bonilla Baldares 1957: 166) y fue "(...) la primera que escribió teatro para niños" (Castro Rawson 1971: 209). Su revista San Selerín "fue la primera revista infantil de calidad en el país" (Castro Rawson 1971:

Dra. Gilda Pacheco Acuña. Profesora de la Escuela de Lenguas Modernas, Universidad de Costa Rica. San Pedro de Montes de Oca, San José, Costa Rica. 
209-10). Por lo tanto, no es de extrañar que la primera biblioteca de literatura infantil lleve su nombre, así como los premios literarios de este género que se otorgan en el país.

El gran interés que Carmen Lyra sintió por los niños no sólo puede verse en su función como educadora o escritora, sino también en otras actividades. Por ejemplo, Carmen Lyra fue la única mujer integrante de la junta del Patronato Nacional de la Infancia cuando esta institución se inauguró en 1930 (Molina Jiménez 2000: 22). Además, entre sus luchas sociales, la preocupación por los niños siempre estuvo presente. Por ejemplo, en su discurso para celebrar el día del trabajador (que tuvo lugar por primera vez en 1913), Lyra inicia sus palabras de la siguiente manera: "Hablo especialmente a los niños ${ }^{2}$, hijos o hermanos de los obreros ..." (González Araya 1996: 20)

A partir de estos hechos, se comprende fácilmente por qué Luisa González y Carlos Luis Sáenz afirmaron que en Cuentos de mi tía Panchita "Carmen Lyra escribió para los niños" (Sáenz Elizondo y González 1998: 12); y que Luis Abreu, analizando esta misma obra, nos dijera que Lyra "sabe hacer más niños a los niños ${ }^{4}$, que es la única manera de hacerlos hombres" (Abreu Gómez 1950: 16); y que Carmen Naranjo afirmara que Lyra estuvo "plenamente realizada en su entrega al niño costarricense [lo cual va paralelo] al gesto creador" (Lyra 1975: I). Además, en relación con la obra objeto de análisis, Naranjo expresa que "Cuentos de mi Tía Panchita es el libro más querido por los costarricenses... [pues] responderá siempre a su deseo de crecer como creció Carmen Lyra, en bondad y en inteligencia" (Lyra 1975: II).

Por su parte, la autora misma es quien nos expresa en el prólogo de sus Cuentos, que su Tía Panchita "tenía el don de hacer reír y soñar a los niños" (Lyra 1994: vi) ${ }^{5}$. Sin embargo, según mi relectura de la obra de Carmen Lyra, su Tía Panchita hace mucho más con esos cuentos. Tanto los niños como los adultos no sólo sueñan, sino que también piensan y reflexionan. En este caso, surgen varias preguntas: ¿es su obra sólo para niños?; ¿son sus metas solamente hacer reír y soñar?; ¿es su colección de cuentos una representación fiel de la literatura infantil? Considero que es el momento oportuno para explorar un poco este género literario, para luego analizar Cuentos de mi tía Panchita desde la perspectiva de la literatura infantil.

Al igual que en otros campos o géneros, el hecho de definir un término es siempre bastante utópico, problemático o polémico y el caso de la literatura infantil no es la excepción. En este sentido, primeramente se discutía si este género era literatura o no. En otras palabras, la discusión giraba en torno a su existencia misma. Después se discutió si este género tenía el mismo valor o rango artístico de la literatura en general. Se cuestionó si la literatura infantil como género podía ser definida como literatura escrita para los niños, por los niños o sobre los niños. Tampoco había consenso en cuanto a sus características, pues mientras que para unos este tipo de literatura debía exponer lo bello, lo positivo y los grandes valores, para otros el niño debía ser enfrentado con la realidad, con lo negativo, con la maldad. En fin, su naturaleza, valor literario y componentes fueron cuestionados al principio. Quizás, en parte, esta polémica se deba a lo reciente que resulta este término, cuando se compara con otros géneros literarios. Aunque los cuentos, desde su tradición oral, han sido una de las formas más antiguas de literatura, la literatura infantil, como género propio, comienza a definirse a principios del siglo XX. Su esencia y funciones no se comienzan a discutir y a cuestionar sino hasta mediados de ese mismo siglo.

Debo aclarar que el objetivo de este artículo no consiste en presentar la definición más completa o precisa de la literatura infantil (lo cual resultaría totalmente imposible), sino en 
exponer varias definiciones para analizar sus variantes y características, con el fin de demostrar el modo en el cual la obra de Carmen Lyra se ubica dentro de este género literario.

Margarita Dobles Rodríguez define la literatura infantil como "un género que incluye obras escritas especialmente para los niños, obras surgidas del folklore y otras de la pluma de los grandes creadores de la Literatura Universal. No es un género... que diga sólo para los niños, aunque sí debe tener ciertas características de fondo y forma que lo hagan asequible a los pequeños" (Dobles Rodríguez 1980: 7-8). Consciente de lo problemático de este término, Dobles propone que en lugar de utilizar el término "literatura infantil", se diga "literatura para niños" (8).

También, mostrando recelo sobre el término mismo, que en inglés es "Children's Literature" (literalmente: literatura de niños), Peter Hunt en su obra Criticism, Theory \& Children's Literature (1991) afirma que el concepto "Children's literature" es una contradicción de términos, ya que es una literatura que se le impone al niño y que, además, es controlada y creada por el adulto (Hunt 1991: 23). Esta denuncia acerca de la imposición o control del adulto sobre dicho género es también compartida por Jill May, quien dice que aunque la primera audiencia para este tipo de literatura sean los niños, ellos no son los que ejercen la autoridad (May 1995: IX) en cuanto a creación, distribución y selección se refiere.

En relación con los problemas de definición que presenta este término, Hunt ahonda más en el proceso descriptivo y trata de definir lo que es la literatura y lo que es el niño, para concluir que la literatura infantil puede ser definida como libros leídos, apropiados o satisfactorios para miembros de un grupo llamado "niños" (Hunt 1991: 61). Lo irónico de esta definición consiste en que el grupo en cuestión es presentado por Hunt como elitista o exclusivo; pero en realidad, de acuerdo con Alison Lurie, "Todos nosotros fuimos miembros de esta tribu: todos conocíamos sus costumbres, maneras y rituales" (Lurie 1990: IX). En otras palabras, todos hemos pertenecido a este grupo, ya que todos hemos sido niños, hemos sido miembros de ese club tan selecto y especial y los más afortunados de nosotros, los adultos, son aquellos que pueden conservar en su ser un poco de esa esencia infantil.

Habrá muchos conceptos más de literatura infantil, los cuales serán definidos por cada autor o crítico de acuerdo con su interés, formación o experiencia. Unos enfatizarán en la función o la finalidad; otros, en la forma; y otros más, en la temática, en el estilo o en la ideología. Si partimos por ejemplo de la definición de Literature for Children (literatura infantil) que puede hallarse en la internet, es decir, la literatura que le habla al niño, podremos advertir que, de acuerdo con esta concepción, no sólo se contemplan los libros escritos para ellos, sino también revistas, películas, grabaciones, escritores, bibliotecarios y publicistas; en fin, todos los medios y las personas que contribuyen a acercar al niño a la literatura. Obviamente, una definición tan global y general como esta presenta varios problemas. Por lo tanto, en este caso es mejor volver a nuestra autora, Carmen Lyra, para presentar su propia definición de literatura infantil, dada en la bella metáfora que ella utiliza para describir los Cuentos de [su] Tía Panchita: "eran humildes llaves de hierro que abrían arcas cuyo contenido era un tesoro de ensueños" (Lyra 1994: iii). Al reflexionar sobre esta metáfora, podemos ver que no se trata sólo del hecho de tener la llave apropiada, sino también de tener la capacidad para valorar el tesoro de esta arca, lo cual hará al lector o al oyente y al niño o al adulto disfrutar la literatura infantil.

Ahora bien, en relación con la naturaleza de este género, los libros consultados y algunas de las tesis analizadas coinciden en tres aspectos que consideran parte de la literatura infantil: la presencia de elementos folclóricos, el conflicto entre la realidad y la fantasía y la 
finalidad de los textos infantiles. Por lo tanto, es conveniente ahora explorar un poco estos tres temas y observar cómo funcionan dentro de la obra de Carmen Lyra.

\section{La presencia de elementos folklóricos en la literatura infantil y en Cuentos de mi Tía Panchita}

Comencemos por el folclor. De acuerdo con Marta Madrigal, el folclor puede definirse como "el conjunto de manifestaciones culturales, tanto de carácter espiritual como social y material que se da en el seno de las clases populares" (Madrigal Abarca 1995: 13). Los cuentos, entonces, son reflejos de estas manifestaciones culturales y populares. Por ejemplo, en Cuentos de mi Tía Panchita, el aspecto popular es relevante, pues se da en la forma y en el contenido. El lenguaje del relato, las características y restricciones del medio, el desenlace del cuento y las condiciones, reflexiones y acciones de los personajes, reflejan lo popular.

Esta muestra de cultura popular es respaldada por la presencia de una narradora que fomenta no solo la tradición oral, sino también la veracidad del relato mismo. Además, recordemos que Carmen Lyra pertenece al grupo de escritores costumbristas, quienes generan "textos dedicados a los niños... [en los que se] manifiestan las costumbres y tradiciones del pueblo costarricense usando tanto el lenguaje vernacular como expresiones populares (Madrigal Abarca 1995: 55). Además, en el caso particular de Carmen Lyra, "hay siempre un marcado costumbrismo, por su espíritu observador hondamente arraigado en su país y en su gente" (Castro Rawson 1971: 210).

Por otro lado, el folclor es una de las fuentes de la literatura infantil "porque, como proviene del alma popular, responde directamente al alma del niño... [Además,] es fácil comprender que la manera de pensar, sentir y expresarse de la mente popular en las etapas de la infancia de la humanidad, coincidan y acierten con la manera de ser y expresarse del niño" (Dobles Rodríguez 1999: 79). Así, este “diálogo de almas" se ve claramente en la obra de Lyra, pues su gran interés por los niños facilita dicha comunicación espiritual.

Cullinan y Galda afirman que de la misma manera que el folclor ofreció explicaciones del mundo a la gente de siglos atrás, este ayuda a los niños a entender nuestro mundo actual (1994: 164). Esta analogía entre el niño y la infancia de la humanidad la considera también Alison Lurie en su libro Not in Front of the Grown-ups. Precisamente, en su último capítulo, titulado "El folclor de la niñez", la autora afirma que la infancia es una sociedad primitiva con sus rituales, creencias, costumbres y literatura, en la cual "el desarrollo del ser es paralelo al desarrollo de una raza"7 (Lurie 1990: 217). Será interesante, entonces, ver cómo este folclor paralelo se presenta en la obra de Carmen Lyra.

En cuanto al folclor como tal, no ahondaré más en él, pues este ya ha sido discutido minuciosamente por Madrigal en su tesis, quien además explora los términos folclorismo, folclorización y folclorística, haciendo referencia al texto de Lyra. También en Vásquez (1989) se presenta una perspectiva interesante del folclor, pues se cita a Lombardi Satrini, quien señala dos funciones básicas de este: "una la de impugnar la cultura hegemónica y la otra la de servir como narcotizante" (34). Por eso Vázquez afirma que su tesis "buscará demostrar que Cuentos de mi Tía Panchita, es un elemento que, antes que impugnar una situación social, contribuye a mantenerla" (34). Seguidamente, como ilustración, analizaré algunos elementos o rasgos folclóricos de dos de los cuentos de Carmen Lyra. Aclaro que 
este análisis no se concentrará ni en la expresión como rasgo propio del lenguaje ni en los refranes, pues son temas que ya han sido tratados en otras investigaciones.

Cuentos de mi Tía Panchita presenta dos tipos de relatos: el del primer núcleo, constituido por cuentos de hadas, y el del segundo núcleo, integrado por los cuentos de Tío Conejo, los cuales se clasifican, a su vez, como cuentos de animales. Considero prudente analizar un cuento de cada núcleo para ver cómo lo folclórico se manifiesta en la obra. Del primer grupo tomaré "La casita de las torrejas", pues resultará interesante ver lo popular o folclórico del pueblo costarricense dentro de un cuento de hadas tan clásico y conocido como lo es "Hansel y Gretel", del cual se han encontrado versiones parecidas en pueblos africanos, entre los indios americanos y en otras sociedades, aunque cada grupo o comunidad lo ha modificado para reflejar sus propias condiciones y creencias.

Primero es conveniente repasar algunas de las características de los cuentos de hadas, con el fin de ver si estas se presentan en la obra de nuestra autora nacional. Al respecto, Víquez señala que los cuentos de hadas son una representación pura del género maravilloso, ya que presentan dos planos de leyes: naturales y sobrenaturales (1976: 99). Además, estos relatos están poblados de personajes pasivos e incapaces de vencer sus problemas por sí mismos, por lo cual necesitan "ayuda mágica". Asimismo, en estos cuentos se señalan la obediencia, la bondad y la compasión como los principales atributos del héroe o de la heroína.

Por otro lado, May (1995: 92) señala que estos cuentos enfrentan al individuo con la sociedad y fomentan la conformidad social, aspecto que también fue señalado por Víquez. Sin embargo, Allison Lurie ve estos textos como subversivos, ya que favorecen a los miembros más desposeídos de la sociedad: niños, mujeres y pobres. También, Lurie considera que estos son textos en los cuales la ley y el orden no siempre se respetan (1990: 32). Veamos, pues, si es sumisión o subversión lo que Carmen Lyra presenta en su obra.

Tanto en "La casita de las torrejas" como en los otros relatos de Cuentos de mi Tía Panchita, lo folclórico, lo popular y lo "tico" son componentes esenciales de la temática, estilo y discurso narrativo de Carmen Lyra. Nuestra autora nos presenta a dos "chacalincitos" huérfanos, quienes al no tener una "burusca con que encender el fuego... Atrancaron la puerta y agarraron montaña adentro" (Lyra 1994: 91). Vemos entonces cómo la versión de los Hermanos Grimm de "Hansel y Gretel” sufre varios cambios drásticos en la prosa de Lyra. En su relato no hay un padre débil de carácter ni existe una madrastra perversa. Los niños están totalmente solos, huérfanos. Lyra, mostrando una vez más su gran interés por nuestros niños, introduce el problema del desamparo total que aqueja a nuestra sociedad. Sus "chacalincitos" 8 son pobres, tienen hambre y están completamente solos. Además, ellos son los que forjan su propio destino, pues no hay madrastra que los pierda o engañe, ni padre que la secunde. Los niños, por sí mismos, deciden "irse a rodar tierras", deciden "subirse a un palo" para pasar la noche y deciden acercarse al lugar donde divisaron "la lucecita" la noche anterior. No obstante, estos niños temen padecer hambre o ser devorados por animales del bosque, aunque no le temen a la soledad. Quizás se trate de "la soledad del enmontañamiento" señalada por Constantino Láscaris en el folclor nacional (1985: 385).

La casita, en "Hansel y Gretel”, es más fantástica si se quiere, pues está "recubierta de pasteles y los cristales de la ventana eran de azúcar blanca" (Grimm y Grimm 1998: 65). La casita descrita por Carmen Lyra está a la orilla de la montaña y lo atrayente en ella es una cazuela de torrejas recién hechas, pues los niños perciben "un olor como a miel hirviendo" (Lyra 1994: 91), y como ellos "estaban hilando de hambre" (91), se "arrimaron" a la ventana 
y se "cacharon" una torreja. Entonces, la casita de las torrejas resulta ser más realista, pues no tiene paredes de dulce ni ventanas de azúcar. Además, en este cuento se ilustra la costumbre de las gentes de campo de poner a enfriar en la ventana el pan o pastel recién hecho. Si bien las torrejas $^{9}$ no son un alimento exclusivo del ámbito costarricense ${ }^{10}$, estas sí fueron muy populares en nuestro país a principios de siglo. En sí las torrejas son un alimento semejante a lo que hoy en día conocemos como tostada francesa. Incluso actualmente en ciertas regiones de Costa Rica las torrejas continúan siendo populares. No obstante, lo curioso es que si se pregunta ahora por la descripción de una torreja, las respuestas, al menos en San José, son bastante diversas: "es como un prestiño"; "es como un tipo de cajeta"; "es como una oreja"; "es un tostel"; "es una galleta". Además de la diversidad de respuestas, resulta también curioso que todas las personas a quienes se les consultó sobre esta palabra, mencionaron como punto de referencia el mismo cuento: "es como en 'La casita de las torrejas de Carmen Lyra", decían.

El hambre como problema social introduce otro problema también muy común en nuestra sociedad: el robo. Así, la frase en la versión de los Hermanos Grimm pronunciada por una voz suave que exclama: "Mordisquito, mordisquita,/ ¿quién mordisquea mi casita?" (Grimm y Grimm 1998: 65) se transforma en una voz ronca en el cuento de Lyra que grita: “Piscurum, gato no me robés ${ }^{11}$ mis torrejas! “(Lyra 1994: 91) Además, Lyra es más directa en su relato. Su bruja no es primero una viejecita que les ofrece manjares y camas blandas a los niños. No, la bruja descrita por Carmen Lyra desde el principio muestra ser "más mala que el mismo Patas" (Lyra 92), pues agarra a los niños "por las orejas", los "arrastra" a la casa y les dice abiertamente que se los va a comer; pero antes les dice que los va "a engordar como a unos chanchitos, para darse cuatro gustos con ellos" (92). Así, mediante figuras literarias y expresiones populares, sus intenciones son bastante claras.

La bruja del relato de Lyra es más "pareja”, o quizás, más pobre. Mientras que en "Hansel y Gretel" la bruja sólo se quiere comer a Hansel, en "La casita de las torrejas", la bruja les da desperdicios a los dos niños por igual ${ }^{12} \mathrm{y}$, por supuesto, la bruja quiere devorarse a los dos niños. Esto podría interpretarse como una muestra de pobreza, la cual también se observa en el recurso que los niños utilizan para engañar a la bruja. Mientras que en "Hansel y Gretel" los niños usan un huesito de pollo para hacerle creer a la bruja que Hansel no ha engordado, en "La casita de las torrejas" los niños enseñan "una colita de ratón", pues no hay huesos a mano, debido a que los desperdicios que comen tienen que devorarlos por completo. Además, nótese que la bruja de "Hansel y Gretel" nunca descubre el engaño, pero en el relato de Carmen Lyra, la bruja, aunque "pipiriciega", sí se da cuenta de que la estaban "cogiendo de mona" (Lyra 1994: 92).

En "La casita de las torrejas", las líneas relacionadas con la comida, las cuales corresponden a las escenas desarrolladas en la cocina, muestran muchos elementos folclóricos. La bruja quiere hacer una buena "fritanga" con los niños. Los "chiquillos" atizan el fuego y "friegan los trastos", mientras la bruja "pone una gran olla sobre los tinamastes" (Lyra 1994: 93). Muchos de estos términos los emplea Constantino Láscaris en la sección dedicada al folclor en su libro El costarricense, cuando introduce la descripción de una casa de principios del siglo XIX, la cual estaba provista "con un buen fogón de tinamastes y horno grande para el amasijo" (Láscaris 1985: 410).

El baile, como manifestación cultural y social, bastante popular en nuestra sociedad, puede considerarse como otro elemento folclórico presente en este cuento de Lyra. La bruja quiere que los niños se "echen una bailadita" sobre una tabla para empujarlos más fácilmente 
a la olla y así "sancocharlos". Pero como ellos fingen que no saben, entonces es la bruja quien les da el ejemplo. Al verla, los niños inclinan la tabla y es la bruja quien "fue a dar ¡chupulún! a la olla de agua hirviendo" (Lyra 1994: 94). No obstante, no se le debe culpar, pues "A los costarricenses les gusta bailar. En cuanto tienen la ocasión de bailar, la aprovechan" (Láscaris 1985: 404). Además, es importante destacar que la figura de la bruja presentada por Lyra, a pesar de sus variantes, sigue la tradición folclórica europea medieval, pues es ruin y malvada. La imagen de la bruja en el folclor nacional es diferente: hace el bien, ve el futuro, es curandera y vende "polvos de cuyeo" (Láscaris 1985: 346).

Al contrastar las dos parejas de niños en ambos cuentos, pueden apreciarse diferencias que muestran lo nacional o lo popular en la versión de Carmen Lyra. Sus "chacalincitos" son "sumisos" y necesitan ayuda. Además, como lo menciona Víquez en su tesis, la "ayuda mágica" les viene de una mutación religiosa generada por medio de la imagen de un viejecito quien resulta ser "Tatica Dios"13. Es Él quien les da información y los consejos necesarios para que los niños puedan escapar de la bruja, pues sin su ayuda, los niños hubieran sido devorados. En realidad, se trata del arquetipo del viejo sabio que ayuda al héroe en su lucha. ¿Será la pasividad del costarricense o la fe religiosa de este lo que la autora deja ver entre líneas?

Lo cierto es que estos "chiquillos" de Lyra tienen que pasar más trabajos que Hansel y Gretel, quienes no tienen que preocuparse por la bruja, pues esta se consume en el horno; más bien, Hansel y Gretel encuentran en todos los rincones de la casa cofres llenos de perlas y piedras preciosas. Por el contrario, los "chacalincitos" de "La casita de las torrejas" deben sacar a la bruja de la olla y enterrarla, y deben registrar la casa para encontrar barriles con monedas de oro, lo cual nos recuerda las famosas leyendas de botijas del folclor nacional. Claro que ellos no tienen que compartir su hallazgo con un padre arrepentido, como en el caso de Hansel y Gretel, puesto que "todo les tocó a ellos" (Lyra 1994: 94). Así, los niños desamparados, quienes aconsejados por "Tatica Dios" se mostraban "sumisos", transgreden el orden moral establecido, pues no solamente matan a la bruja, sino que también se apoderan de sus riquezas. A partir de este hecho, podemos observar que a estos niños se les justifican sus actos delictivos, pues no reciben ningún tipo de castigo.

Volviendo a la pregunta que nos planteamos anteriormente relativa a la existencia de sumisión y subversión en la literatura infantil, al contrastar la idea de subversión que señala Allison Lurie en los textos infantiles con la temática de sumisión que menciona Jorge Víquez como característica propia de los cuentos de hadas, vemos en este cuento de Lyra la presencia de ambas. Los sumisos "chacalincitos" huérfanos, atrapados por la bruja, necesitan "ayuda mágica". Sin embargo, al final del relato, estos niños actúan, matan a su opresor, es decir, son subversivos. Así, en este cuento de Carmen Lyra, observamos cómo coexisten la sumisión y la subversión en los personajes protagónicos. Estos dos aspectos no resultan contradictorios, sino que trabajan en armonía para lograr el desenlace feliz del relato de Carmen Lyra titulado "La casita de las torrejas".

Los cuentos de animales son también reflejo del folclor de un pueblo, pues las prosopopeyas presentan microcosmos humanos. Cada animal tiene cualidades, defectos, vicios o atributos que reconocemos en los hombres y las mujeres de nuestra sociedad. El segundo núcleo de relatos de Cuentos de mi Tía Panchita, es decir, los cuentos de Tío Conejo, es un ejemplo claro de este tipo de literatura. En comparación con el primer núcleo, estos relatos resultan ser más realistas, menos complejos y más dialogados. Lo que Tío Conejo y sus amigos o enemigos digan, hagan, teman o deseen, refleja en cierta forma la idiosincrasia de nuestro pueblo. Desde 
la perspectiva de los elementos folclóricos, analizaré un cuento del segundo núcleo, llamado “Tío Conejo y el caballo de Mano Juan Piedra".

El cuento se inicia con un evento social: el matrimonio de Tío Periquito Sapoyol con Tía Cotorrita, del cual Tío Conejo es nada menos que uno de los padrinos. Tradiciones y costumbres de dicho evento se observan en el texto: "La parranda era -como es costumbre- en la casa de la novia... [donde se iba] a bailar toda la noche" (Lyra 1994: 179). Además, se presenta la costumbre de madrugar -característica de muchos costarricenses-, pues la Tía Panchita nos dice: "Desde que comenzaron las claras del día ya estaba mi señor [Tío Conejo] arriba" (179). También, el vestirse o "acicalarse" para tal ocasión puede observarse en el chaquetón de casimir azul que Tío Conejo se pone junto con el pañuelo de seda y el sombrero de pita, para asistir a tal evento. Lo galán del tico también está presente, pues Tío Conejo ve a la novia y dice: "Campo y anchura, que aquí va la hermosura!" (179). Además, en el menú de la fiesta se ofrecen platos muy típicos: "había frito, pozol y la consabida torta de arroz con leche" (180).

Sin embargo, el conflicto en este relato no se origina en "la comedera", como la llama Constantino Láscaris, sino en "la bebedera"14. Así, en la fiesta de bodas, Tío Conejo se "escurrió" una botella de rompope "bien cargadita de guaro" (Lyra 1994: 180) y al ver un caballo ajeno, "a él que nada le faltaba y con los tragos, se envalentonó, [...] le echó un bozal con un mecate que traía la bestia [y] se encaramó como si fuera el dueño... “ (180). Pero la pericia de Tío Conejo no se ve en el robo del caballo, sino en cómo lo justifica y lo hace necesario. Cuando el verdadero dueño, Juan Piedra, le reclama, entonces el labioso y mentiroso de Tío Conejo replica, “¿No ve que anoche se me metió [su caballo] en el frijolar y se lo comió casi todo? [...] Otro día tenga más cuidado antes de amenazar a la gente honrada" (181). Y como el tico no es hombre de pleitos, Juan Piedra le contesta "que vale más un mal arreglo que un buen pleito. A ver, ¿cuánto vale el daño?” (181). Claro está que Juan Piedra pide rebaja, algo muy típico también. Pero en el fondo, Juan Piedra se siente muy culpable, pues lo que supuestamente su caballo ha hecho no tiene nombre: meterse en el frijolar y comérselo todo es considerado un delito nacional, ya que "es un hecho, el costarricense come frijoles y si puede, los come para desayunar, para almorzar y [...] para cenar... [Así,] podrá faltar la carne, podrá faltar, aunque sería triste, el huevo duro encima, podrán faltar, aunque ello sería lamentable, las tortillas; pero no pueden faltar los frijoles" (Láscaris Commeno 1985: 252).

\section{La realidad y la fantasía en la literatura infantil y en Cuentos de mi Tía Panchita}

El tema realidad-fantasía es otro aspecto clave de la literatura infantil y, en realidad, es uno de los más polémicos. Muchos críticos favorecen lo realista de los cuentos infantiles, pues presenta al niño un mundo que él conoce o con el cual puede adquirir experiencia para enfrentar el mundo real; es decir, estos críticos defienden "la necesidad de realismo, de acercamiento a la vida cotidiana" (Pérez Yglesias 1989: 61). Dentro de esta línea de pensamiento, algunos señalan que lo irreal o lo maravilloso puede incluso ser nocivo para el niño. Sin embargo, Bruno Bettelheim responde a este temor diciendo que los cuentos de hadas, al mismo tiempo que deleitan, instruyen. Como psicoanalista, Bettelheim comenta que la falta de "magia" o fantasía y que la exposición prematura a la realidad pueden ocasionar problemas 
en el niño, los cuales serán percibidos en su adolescencia, cuando él tenga la necesidad de buscar substitutos para ese escape necesario de la realidad (Lurie 1990: 39-40).

Cullinan y Galda (1994: 200) nos dicen que la fantasía abre puertas a mundos de imaginación que enriquecen e iluminan las vidas de los niños, porque estas historias presentan grandes complejidades: la relatividad del tamaño, del espacio o del tiempo y la valentía del individuo y su integridad, entre otros temas. Estas dos autoras toman en cuenta la definición de fantasía de la escritora Susan Cooper, la cual presenta este concepto de fantasía-imaginación como "la metáfora por la cual nos descubrimos nosotros mismos"15 (200).

Finalmente, es nuestra Carmen Lyra quien favorece el papel de la imaginación y la fantasía cuando, en el prólogo de su obra, nos dice con ironía: “(...) gentes muy prudentes y de buen sentido, reprochaban a la vieja señora [la Tía Panchita] su manía de contar a sus sobrinos aquellos cuentos de hadas, brujas, espantos, etcétera, los cuales, según ellas, les echaba a perder su pensamiento" (1994: iii). Sin embargo, no son las enseñanzas de su tío Pablo, profesor de lógica, las que le dan confianza y despiertan en Carmen Lyra el interés por la escritura, sino aquellos cuentos fantasiosos de su Tía Panchita.

El interés infantil es lo que Dobles toma en cuenta en su clasificación y observación sobre el papel de la realidad y la fantasía dentro de la formación del niño. Basándose en la edad del niño, Dobles establece la necesidad de estos dos aspectos (realidad y fantasía) y clasifica la infancia en tres fases: la primera, que llega hasta los dos años; la segunda, que va de los dos hasta los seis años; y la tercera, que corresponde a la edad escolar, es decir, de los siete a los doce años. Sobre la segunda infancia, la autora nos dice: "El interés se vuelca hacia el mundo abigarrado de objetos, animales y gentes que lo rodean. Es el momento de la curiosidad, la imitación, el animismo y el inicio, al final, de la fantasía" (Dobles Rodríguez 1999: 93). En cuanto a la tercera infancia, Dobles destaca que hay "un juego de imaginación creadora muy rico y muy estimulador de la inteligencia y la inventiva. Es la época en que el cuento de maravilla se roba el interés de los pequeños de primero y segundo grados" (93). Luego, esta misma autora añade que en el segundo ciclo de primaria, el niño comienza a interesarse en cuentos más realistas.

Realmente, en los cuentos de Carmen Lyra, no veo un conflicto entre la realidad y la fantasía, sino un equilibro entre ambas. Se ha dicho que sus cuentos del primer núcleo pertenecen más al género de lo maravilloso, pues son cuentos de hadas, mientras que los pertenecientes al segundo núcleo, es decir, los de Tío Conejo, son más realistas. Estos hechos son ciertos, pero también es cierto que existe mucho realismo en sus cuentos maravillosos y mucha fantasía en los cuentos de Tío Conejo. En sus cuentos de hadas, por ejemplo, el "Había una vez" no es tan distante ni tan remoto como el de los cuentos de Perrault o de los Hermanos Grimm, pues la autora, mediante el lenguaje popular, nos acerca a ese mundo. Para ilustrar este aspecto, haré referencias sobre dos cuentos de su primer núcleo: "La mica" y "El cotonudo".

El lenguaje popular es uno de los elementos esenciales y característicos de la narrativa de Cuentos de mi Tía Panchita. Por ejemplo, en "La mica", Lyra nos dice que había un rey que estaba triste porque encontraba a sus hijos "algo mamitas" y quería "sacarlos de entre las enaguas de la reina" (Lyra 1994: 53). En "El cotonudo", la autora escribe que "había una vez una viejita que tenía un hijo galanote... tan limpio que parecía un ajito, con los pies descalzos tan lavados y blancos, que daba lástima mirarlos caminar entre los barriales" (Lyra 1994: 65). Por otra parte, al oír hablar a los reyes o príncipes de Lyra, parece que estamos oyendo a un 
campesino costarricense: “Upe, ña María..." (53) dice un príncipe en "La mica”. Asimismo, al oír las pintorescas descripciones de sus relatos, nos acercamos a nuestro campo, a nuestro suelo. La princesa en "El cotonudo", por ejemplo, es descrita de la siguiente manera: "era un primor de bonita, con una cabeza que era como ver el sol de rubia y en la que cada hebra era crespa como un quelite de chayote"16 (65).

Además, lo maravilloso a veces no es muy significativo en estos relatos. Los príncipes en "La mica" nunca se sorprenden de que esta pueda hablar. Lo que los sorprende y alarma es que la mona quiera casarse con ellos. El encantamiento del príncipe en "El cotonudo" no es muy relevante, pues lo que importa es que "el cotonudo" tenga los medios para casarse con la princesa. Hay mucho realismo en la desesperación del "cotonudo" y en sus pensamientos suicidas. También existe mucho realismo en la hipocresía del rey, quien al ver que su yerno, "el cotonudo", ya no es un "chonete" sino poseedor de riquezas, lo acepta sin reparos. Así, tanto la lengua popular como las descripciones de Carmen Lyra acercan lo maravilloso a lo real en sus relatos.

En relación con los cuentos de Tío Conejo, vemos que la fantasía juega un papel esencial en ellos. Después de todo, tiene que haber fantasía para poder aceptar que los animales hablen, piensen y actúen como humanos ${ }^{17}$. Para ilustrar esta idea haré referencia a dos cuentos del segundo núcleo: “Por qué Tío Conejo tiene las orejas tan largas?” y “CCómo Tío Conejo le jugó sucio a Tía Ballena y a Tío Elefante?”

Al igual que el niño, el adulto tendrá que usar mucha imaginación para aceptar que Tío Conejo, en el primer cuento mencionado, vaya a hablar con "Tatica Dios" montado en un "zopilote", o que una ballena esté coqueteando con un elefante, como se ve al principio del segundo relato. Pero el uso de la imaginación es diferente. Pienso que el niño necesita utilizar su imaginación y fantasía, las cuales él posee en mayor grado, para visualizar cómo Tía Ballena y Tío Elefante están en la playa "en gran conversona" (Lyra 1994: 147). El adulto necesitará acudir a su imaginación y fantasía para aceptar que estos dos animales estén juntos en un mismo sitio. El niño usará su imaginación para visualizar cómo Tatica Dios le jala las orejas a Tío Conejo, mientras que el adulto necesitará también mucho de su imaginación para aceptar un mundo donde un conejo pueda matar a un tigre, a un león y a un lagarto.

Sin embargo, el temor de Tío Conejo de que dos fuerzas puedan "unirse para gobernar toda la tierra” (Lyra 1994: 147), presente en “¿Cómo Tío Conejo le jugó sucio a Tía Ballena y a Tío Elefante", es real, pues también los seres humanos lo experimentan. La forma en que Carmen Lyra lo desarrolla en su cuento es lo que evoca la imaginación y la fantasía. El deseo de Tío Conejo de ser más grande para que no abusen de él, presente en “¿Por qué Tío Conejo tiene las orejas tan largas?", es también real, pues muchas personas desean lo mismo. También en este caso, la forma en la que este deseo es presentado en el cuento es lo que exige hacer uso de la imaginación y la fantasía.

En realidad, seguir explorando estos dos términos nos llevaría a discutir muchos aspectos importantes de carácter social, ideológico, psicológico e histórico. La discusión de estos aspectos sería un buen punto de partida para iniciar otras investigaciones sobre Carmen Lyra. Pero uno de los temas que está bastante ligado a este conflicto realidad-fantasía es la finalidad del cuento infantil. 


\section{Algunas de las funciones de la literatura infantil presentes en Cuentos de mi Tía Panchita}

La finalidad de la literatura infantil es un tema bastante amplio y polémico que no pienso desarrollar; simplemente me limitaré a presentar algunas observaciones sobre los objetivos de este tipo de literatura contemplados dentro de la obra Cuentos de mi Tía Panchita. Por ejemplo, una perspectiva común señala la función de deleite o entretenimiento de los cuentos infantiles. Quizás esta sea la visión más prosaica, pero es también bastante cierta. En realidad, esta es una función clásica de la literatura en general. En la obra de Lyra, ese deleite se da tanto en la forma como en el contenido. Sus expresiones populares, sus dichos y ocurrencias hacen reír a más de uno. Asimismo, las diabluras de Tío Conejo, la forma de narrar de la Tía Panchita y las mismas tramas de cada relato deleitan a todos.

Otra de las funciones señalada como finalidad propia de la literatura infantil es su función didáctica. Dentro de este enfoque, se observan dos tipos de enseñanza: la de tipo lingüístico pedagógico (pues el niño aprende el lenguaje y ejercita su lectura) y la moralista, ya que el niño aprende valores. Quizás sea dentro de esta finalidad didáctica donde se ha generado más controversia en torno a la obra de Carmen Lyra.

Vásquez señala que la finalidad de la enseñanza de la lengua está en conflicto en Cuentos de mi tía Panchita por no tratarse de un lenguaje culto sino el propio del relato popular. Por su parte, Madrigal señala que los valores en esta misma obra son bastante relativos y que, incluso, en los cuentos de Tío Conejo están invertidos. A pesar de estos hechos, Cuentos de mi Tía Panchita es una obra bastante didáctica, pues aunque no enseña el lenguaje en forma "correcta" (normativamente hablando), enseña el lenguaje de nuestro pueblo, de nuestro pasado, de nuestro folclor. Esta obra enseña que no existen valores fijos, sino que estos cambian o se modifican dentro de varias perspectivas. Entre estas, el diablo puede ser engañado y no ser para nada temido, Tatica Dios puede "estar de malas", la muerte puede ser burlada, el dinero puede dar felicidad a unos y significar la perdición para otros y el embaucador puede triunfar por su astucia. También, dentro de estas perspectivas puede ser posible que lo hecho por unos se considere maldad, pero a la vez, que esas mismas acciones, realizadas por otros, sean consideradas como valor y heroísmo. En fin, con sus cuentos, Carmen Lyra no muestra la vida en blanco y negro, sino que más bien nos presenta lo gris de la existencia humana, es decir, la relatividad o inversión de valores de un mundo que así lo presenta y lo demanda.

Otra finalidad de los cuentos infantiles es la de tipo psicológico. Me refiero a la que contempla estas obras como ejes importantes dentro del desarrollo de la formación de una personalidad balanceada ${ }^{18}$. Esta finalidad se complementa con la de tipo sociológico, la cual, de acuerdo con Pérez (1989: 63), es "la formación de conciencia crítica en los niños [la que] les permite saber algo más y pensar algo diferente". En otras palabras, esta función sociológica tiene como objetivo la formación de una personalidad que sea capaz de enfrentar los problemas, las dudas y los dilemas de la existencia humana. Esta función está presente en la obra de Carmen Lyra. En Escomponte perinola, Juan Cacho aprende a no ser tan crédulo y a no permitir insultos de nadie. La cucarachita Mandinga, aunque "lo siente y lo llora", tendrá que aprender a vivir sin su amado Ratón Pérez. La Tía Venada aprende que las "habladurías" y "rajonadas" no conducen a nada bueno. Y el tonto de las adivinanzas prefiere no casarse con la princesa y dejar así una vida de opulencia a tener que sacrificar su libertad al vivir con las normas sociales de restricción y ética que su nueva condición social le impodría como miembro de la realeza. 
Puesto que el aspecto didáctico del texto de Lyra ha sido objeto de polémica y temor, he decidido retomarlo en la conclusión de mi artículo. En algunos de los trabajos analizados, lo didáctico ha sido visto de diferentes formas: como el código moral presentado por el narrador (Víquez Guzmán 1976), como función ideológica del mismo narrador (Araujo Aguilar et al. 1977), como el rescate de la tradición popular (Madrigal Abarca 1995) y como una "transgresión" de la finalidad lingüística del aparato escolar que, a la vez, podría interpretarse como una legitimación del concepto de costarriqueñidad (Vásquez Solórzano 1989). En cuanto al código moral del texto, hay ideas que en principio se cuestionan: la conformidad o el estancamiento social, señalados por Víquez; el antagonismo entre clases, apuntado por Madrigal; el hecho de cómo lo material se antepone a lo espiritual, comentado en varios estudios; el uso del engaño para hacer justicia; la inversión de valores y la presentación irónica de lo religioso en la obra.

Debido a estos cuestionamientos, considero que el texto Cuentos de mi Tía Panchita sí es educativo; no obstante, esta obra requiere una redefinición del elemento didáctico. En este sentido, debe estimularse al niño para que sea un lector activo. Por lo tanto, la idea de texto didáctico provisto de pocas brechas para que el mensaje sea como una guía y no genere dudas, debe ser abandonada. Con su obra, Carmen Lyra ha demostrado este hecho al generar cuestionamientos y crear dinamismo en el desarrollo de su temática y en su discurso narrativo.

Creo firmemente que Cuentos de mi Tía Panchita es, por una parte, un texto para niños, ya que ayuda a convertirlos en adultos activos y creativos y, por otra, es un texto para adultos, ya que al remontarlos a su infancia, les enseña o les recuerda que el dinamismo y el poder de la imaginación (a veces ignorados) son muy necesarios para vivir mejor.

\section{Notas}

1. La escuela maternal Montessori, en 1925

2. El subrayado no está en el original.

3. El subrayado no está en el original.

4. El subrayado no está en el original..

5. Las siguientes citas de este texto se identificarán con las abreviaturas CTP y con su respectivo número de página.

6. "All of us were at one time members of this tribe: we knew its customs, manners, and rituals."

7. "the development of the individual parallels the development of the race".

8. Nótese que los personajes no tienen nombres propios. Así el problema se plantea en un ámbito social o colectivo, no individual.

9. "Rebanada de pan empapada en vino o leche y rebozada con huevo, frita y endulzada". (DRAE, 1992)

10. La palabra torreja no es costarriqueñismo, ya que según el Diccionario de la Real Academia Española, esta palabra también se usa en América y en algunas partes de España. (cf. DRAE, 1992)

11. El uso del voseo es otro factor que nos ubica en Costa Rica.

12. En la versión de los Hermanos Grimm, Hansel come manjares.

13. Nótese el empleo de un término coloquial ampliamente usado en nuestro país.

14. Láscaris hace énfasis no tanto en lo que se bebe, sino en el acto de beber, y admite que "el mismo es folklórico, y sobre él se ha desarrollado a su vez un folklor propio" (1985: 318).

15. "the metaphor through which we discover ourselves".

16. El subrayado no está en el original.

17. Claro está que de acuerdo con la edad del niño, este hecho será visto y aceptado en forma diferente por él.

18. Esta posición también genera polémica. 


\section{Bibliografía}

Abreu Gómez. 1950. Escritores de Costa Rica. México: Talleres Gráficos de la Nación.

Araujo Aguilar, Patricia et al. 1957. Rasgos comunes de tres categorías de análisis en el relato literario: Análisis estructural de los Cuentos de mi Tia Panchita, Cuentos Viejos, Cocorí y El abuelo cuentacuentos. Tesis de licenciatura: Universidad de Costa Rica.

Bonilla Baladares, Abelardo. 1957. Historia y antología de la literatura costarricense. San José: Editorial Universitaria.

Castro Rawson, Margarita. 1971. El costumbrismo en Costa Rica. 2 ed. San José: Imprenta Lehmann.

Cullinan, Bernice y Lee Galda. 1994. Literature and the Child. 3 ed. Florida: Harcout Brace \& Company.

Dobles Rodríguez, Margarita. 1999. Literatura Infantil. 3 ed. San José: Editorial Universidad Estatal a Distancia.

González, Luisa y Carlos Luis Sáenz. 1998. Carmen Lyra. 2 ed. San José: EUNED.

González Araya, María Nidia. 1996. Carmen Lyra: una voz callada. Tesis de maestría: Universidad de Costa Rica.

Grimm, Jacob y Wilhelm Grimm. 1998. Caperucita Roja y otros cuentos. Roberto Pinzón y David Chericián (trads.). Bogotá: Panamericana Editorial Ltda.

Hunt, Peter. 1991. Criticism, Theory and Children's Literature. Oxford: Basil Blackwell Ltd.

Láscaris Commeno, Constantino. 1985. El costarricense. San José: EDUCA.

Lurie, Alison. 1990. Not in Front of the Grown-Ups: Subversive Children's Literature. Great Britain: Bloomsbury Publishing Ltd.

Lyra, Carmen. 1975. Cuentos de mi Tía Panchita. 7 ed. San José: Litografía e Imprenta Nacional.

1994. Cuentos de mi Tía Panchita. San José: Editorial Costa Rica.

Madrigal Abarca, Marta. 1995. El folclor y la tradición oral en los Cuentos de mi Tía Panchita.

Tesis de licenciatura: Universidad de Costa Rica.

May, Jill P. 1995. Children's Literature and Critical Theory. New York and Oxford: Oxford University Press. 
Molina Jiménez, Iván. 2000. Ensayos políticos: Carmen Lyra y Carlos Luis Fallas. San José: Editorial de la Universidad de Costa Rica.

Vásquez Solórzano, Romano. 1985. El funcionamiento de lo social en un texto literario: análisis de Cuentos de mi Tía Panchita. Tesis de licenciatura: Universidad de Costa Rica.

Víquez Guzmán, Jorge Benedicto. 1976. Los cuentos de mi Tía Panchita: Modelo, género e interpretación. Tesis de licenciatura: Universidad de Costa Rica.

\section{Sitios}

http://www.expreso.co.cr/panchita/ (información sobre el texto Cuentos de mi Tía Panchita)

http://www.comptons.com/encyclopedia/articles/0100/01095424 (información general sobre la literatura infantil)

http://www.upf.com/spring 2000/Lyra.htm/ (información sobre el libro The Subversive Voice of Carmen Lyra de Elizabeth Rosa Horan) 